\title{
Óleos essenciais da Amazônia contendo linalol
}

\author{
V. CAMPBELl DE ARAUJO(1); G. CAMPOS CORREA(1); J. G. SOARES MAIA(1); M. LEÃO DA SILVA(1); O. R. \\ GOTTLIEB(2); M. C. MARX(2); M. TAVEIRA MAGALHÃES(3).
}

\begin{abstract}
SINOPSE
A continuidade da produção de óleo essencial de pau-rosa na Amazônia, não está assegurada, em virtude das dificuldades resultantes da propagação e do crescimento lento da Aniba duckei Kosterm. Com o propósito de resolver o problema se estabeleceram duas linhas de pesquisas : 1. a análise (incluindo variações periódicas da composição) do óleo das fôlhas de pau-rosa (rendimento de 2,0-2,5\%) obtido da Aniba duckei Kosterm. (Lauraceae). 2. um estudo das plantas comuns na Amazônia, quanto a seu teor de linalol, que levou a descoberta do b́leo das fôlhas (rendimento $0,8 \%$ ) obtido de Croton cajuçara Benth. (Euphorbiaceae), contendo mais de $66 \%$ de linalol.
\end{abstract}

A continuidade da produção de óleo essencial de pau-rosa na Amazônia está em perigo. A espécie Aniba duckei Kosterm., rudemente explorada desde 1927, se encontra em vias de extinção, e a descoberta de uma única árvore exige caminhadas cada vez mais longas em regiões cada vez mais distantes (Gottlieb, 1957). Uma maneira de resolver o problema seria, evidentemente, a exploração das fôlhas do paurosa (Gottlieb et alii, 1964), à maneira da indústria extrativa de óleos essenciais de mirtaceas que não sacrifica a árvore. Antes de basear esperanças em tal abordagem era necessário conhecer melhor o óleo essencial das fôlhas e dos galhos finos de pau-rosa.

Com esta finalidade escolhemos para o estudo a árvore 504, existente em solo silicoso, com $23 \mathrm{~m}$ de altura e $24 \mathrm{~cm}$ de diâmetro e idade aproximada de 100 anos, situada entre as picadas I e II, na direção oeste, a $4.150 \mathrm{~m}$ da estrada que atravessa a Reserva Florestal Ducke do Instituto Naciona! de Pesquisas da Amazônia, nas proximidades de Manaus. Entre janeiro de 1970 e janeiro de 1971, cortamos mensalmente um ramo da árvore e o separamos em fôlhas e galhos finos. Ambos êstes órgãos foram submetidos a arraste a vapor e coobação da água destilada. Os óleos foram examinados com respeito a rendimento, índice de refração e teor em terpenos, óxidos de linalol e linalol. Ėstes constituintes foram determinados por cromatografia gás-líquido, utilizando-se uma coluna de Saib-Quadrol (Gottlieb et alii, 1964), em Chromosorb W a $1488^{\circ}$.

Os resultados, inscritos nas Tabelas 1 e 2, mostram que o rendimento em óleo está em estreita dependência com a estação do ano. Na estação chuvosa, quando a precipitação atinge a mais de $250 \mathrm{~mm}$, o rendimento é baixo devido a circulação, relativamente rápida, da água pelas células oleíferas. Já que a eliminação de um constituinte do óleo da célula exige sua solubilização prévia em água, é claro que o linalol, mais solúvel que os óxidos e terpenos, seja eliminado de preferência.

Concomitantemente, com o teor em águd do ambiente, um segundo fator parece afetar a qualidade do óleo. Trata-se da idade das fô. lhas. Quanto mais velhas são, tanto maior a proporção de terpenos e óxidos de linalol que contém, e quanto mais novas, tanto mais ricas são em linalol.

Tôdas estas observações são pertinentes à produção de óleo essencial de fôlhas e galhos finos de pau-rosa. Para que possam ser aproveitados, no entanto, urge agora prosseguir com as experiências de propagação da espé.

(1) - Instituto Nacional de Pesquisas da Amazônia .

(2) - Universidade Federal Rural do Rio de Janeiro.

(3) - Instituto de Tecnologia Alimentar, Ministério da Agricultura. 
T A B ELA 1

COMPOSIÇÃO PORCENTUAL DO ÓLEO ESSENCIAL DAS FÔLHAS DE UMA ÁRVORE DE $A N I B A D U C K E I$

\begin{tabular}{|c|c|c|c|c|c|c|}
\hline colheita & $\begin{array}{c}\text { precipitação } \\
\text { mm }\end{array}$ & fenologia & $\begin{array}{c}\text { rend. } \\
\%\end{array}$ & terpenos & $\begin{array}{l}\text { óxidos } \\
\text { linalol }\end{array}$ & linalol \\
\hline $\mathrm{fev} / 70$ & 260 & velha & & 4.7 & 19.7 & 27.3 \\
\hline $\operatorname{mar} / 70$ & 280 & velha & 1.4 & 1.8 & 15.7 & 49.1 \\
\hline $\mathrm{abr} / 70$ & 270 & velha & & 2.1 & 12.1 & 56.0 \\
\hline $\mathrm{mai} / 70$ & 190 & velha & 1.5 & 1.9 & 18.1 & 37.7 \\
\hline jun/ 70 & 100 & velha + nova & 1.5 & 1.7 & 10.9 & 56.4 \\
\hline $\mathrm{jul} / 70$ & 50 & nova + velha & 2.2 & 2.2 & 6.0 & 66.5 \\
\hline ago/70 & 40 & nova + velha & 2.6 & 2.1 & 8.4 & 70.5 \\
\hline set $/ 70$ & 55 & nova + velha & 1.8 & 2.4 & 10.1 & 50.3 \\
\hline out $/ 70$ & 105 & nova & 2.0 & 1.3 & 5.5 & 70.2 \\
\hline nov $/ 70$ & 155 & nova & 2.0 & 1.5 & 6.0 & 65.1 \\
\hline $\mathrm{dez} / 70$ & 220 & nova & 1.8 & 0.8 & 6.5 & 71.6 \\
\hline $\mathrm{jan} / 71$ & 260 & nova & 2.0 & 0.9 & 5.3 & 85.3 \\
\hline ago/71 & 40 & nova & 2.4 & tr. & 6.4 & 81.6 \\
\hline
\end{tabular}

TABELA 2

COMPOSIÇÃO PORCENTUAL DO ÓLEO ESSENCIAL DOS GALHOS FINOS DE UMA ÁRVORE DE $A N I B A$ DUCKEI

\begin{tabular}{|c|c|c|c|c|c|c|}
\hline colheita & $\begin{array}{l}\text { precipitação } \\
\text { mm }\end{array}$ & fenologia & $\begin{array}{c}\text { rend. } \\
\%\end{array}$ & terpenos & $\begin{array}{l}\text { 6xidos } \\
\text { linalol }\end{array}$ & linalol \\
\hline $\mathrm{fev} / 70$ & 260 & velha & 1.0 & 6.8 & 18.7 & 35.7 \\
\hline $\operatorname{mar} / 70$ & 280 & velha & 1.2 & 4.1 & 11.1 & 62.5 \\
\hline $\mathrm{abr} / 70$ & 270 & velha & 1.5 & 3.1 & 12.5 & 59.8 \\
\hline $\mathrm{mai} / 70$ & 190 & velha & 1.2 & 0.9 & 8.3 & 73.7 \\
\hline jun/ 70 & 100 & velha + nova & 1.1 & 3.2 & 12.3 & 58.7 \\
\hline $\mathrm{jul} / 70$ & 50 & nova + velha & 1.7 & 3.0 & 9.0 & 69.1 \\
\hline ago/70 & 40 & nova + velha & 1.4 & 1.7 & 6.9 & 77.5 \\
\hline set $/ 70$ & 55 & nova + velha & 1.7 & 0.9 & 6.1 & 69.5 \\
\hline out $/ 70$ & 105 & nova & 1.0 & 1.1 & 6.0 & 70.5 \\
\hline nov/70 & 155 & nova & 1.0 & 1.3 & 6.0 & 86.6 \\
\hline $\mathrm{dez} / 70$ & 220 & nova & 2.0 & 1.2 & 4.9 & 94.3 \\
\hline $\mathrm{jan} / 71$ & 260 & nova & & 1.1 & 3.0 & 90.3 \\
\hline ago/71 & 40 & nova & 1.1 & $\operatorname{tr}$. & 2.5 & 97.4 \\
\hline
\end{tabular}

cie por plantío, atualmente em desenvolvimento modesto na Reserva Florestal Ducke do INPA. A maior dificuldade da propagação artificial do pau-rosa na Amazônia é a vulnera. bilidade da planta e pragas (Araujo, 1967). Tão sério é êste problema que nos torna temerosos quanto ao futuro de um empreendimento visando produção de óleo de fôlhas. Po: esta razão estamos atualmente empenhados ainda em outra tentativa de manter a produção de matéria-prima contendo linalol na Amazônia: uma triagem de piantas de crescimento rápido e resistentes à pragas. Por ocasião dêste projeto examinamos o óleo essencial da Euphorbiaceae, Croton cajuçara Benth., que o amazônida conhece sob o nome de sacaca, 
usando o chá de suas fôlhas contra males do figado e do intestino.

Croton cajuçara é um arbusto cujo plantio pods ser realizado por estaca em qualquer tipo de terreno. Adulto pode atingir 3,5 a $4,5 \mathrm{~m}$ de altura. Já 6 a 8 meses após o plantio, no €ntanto, pode se proceder a $1 .^{\circ}$ colheita de fôIhas. Estas fornecem, após secagem, 0,8\% de um óleo essencial cuja análise por CGL consta da Tabela 3. Os materiais e as coildições da coluna foram idênticos aos da colu na empregada na análise do óleo de pau-rosa. A identificação dos componentes foi realizada por tempo de retenção. A presença predominante de linalol no óleo essencial de sacaca foi confirmada por espectrometria de RMN . Com respeito às substâncias que acompanharn o cineol e o linalol no óleo de sacaca, verificamos a ausência de óxidos de linalol e de $\propto$-terpin€ol. $\mathrm{Na}$ amostra analisada existem. no entanto, pelo menos mais 6 constituintes, todos êles com tempo de retenção maior do que o linalol. Entre êsses, os derivados sesquiterpênicos perfazem uns $25 \%$ do óleo. A sua volatilidade, menor que a do linalol, permite sua separação por destilação fracionada, tornando fácil a obtenção de linalol puro.

TABEL 3

COMPOSIÇÃO PORCENTUAL DO OLEO ESSENCIAL DAS FOLLHAS DO CROTON CAJUCARA

\begin{tabular}{l|r|l}
\hline & $\%$ & Identificação \\
\hline & \multicolumn{1}{c|}{$\%$} & \\
terpenos & 1.6 & CGL \\
1,8-cineol & 2.4 & CGL \\
linalol & 66.4 & CGL, RMN \\
\hline
\end{tabular}

Continuaremos estudando o óleo essencial das fôlhas de Croton cajuçara a fim de identificar todos os seus constituintes. Os galhos também contêm óleo, porém em quantidade nitidamente inferior a 0.1 a $0.2 \%$.
Experiências de plantio cia sacaca, já estão em curso, por ora totalmente satisfatório, nd Reserva Florestal Ducke do INPA. De todas as vias de que até agora trilhamos, no intuito de resolver o problema do escasseamento gradativo do pau-rosa, a triagem de plantas nativas, parece, assim, a mais promissora.

\section{AGRADECIMENTOS}

Agradecimentos são devidos ao Conselho Nacional de Pesquisas por suporte financeiro ao presente trabalho.

\section{SUMMARY}

The continuity of resewood oil production in Amazonia is not assured, due to difficulties in propagation and slow growth of Aniba duckei Kosterm. With the purpose of solving this old problem, two lines of research were pursued: 1. The analysis (including seasonal variation of composition) of rosewood leaf (yield 2-2.5\%, and buranch (yield $1-1.7 \%$ ) oil obtained from A. duckei Kosterm. (Lauraceae). 2. A survey of common amazonian plants for linalool content, which led td the discovery of sacaca leaf oil (yield $0.8 \%$ ), obtained from Croton cajuçara Benth. (Euphorbiaceae), containing over $66 \%$ linolool.

\section{BIBLIOGRAFIA CITADA}

Araujo, V. Campbell de

1967 - Sôbre a Germinação de Aniba (Lauraceae). I - Aniba duckei Kostermans (Pau-rosa Itauba). Publ. Inst. Nac. Pesq. Amaz.; Botânica, Manaus, $23: 1-14$.

GotTlieb, O. R.

1957 - Rev. Quím. Ind., Rio de Janeiro, 26(195).

GotTlieb, O. R. ET ALII

1964 - Perf. Essent. Oil Record, 55(253).

Moraes, A. Alpande de et aliI

1971 - Oleos Essenciais de espécies do gênero Aniba. In : $V$ Congresso Internacional de Oleos Essenciais, Säo Paulo. 